\title{
Estimating the burden of HIV late presentation and its attributable morbidity and mortality across Europe 2010-2016
}

\author{
The Late Presentation Working Groups in EuroSIDA and COHERE
}

\begin{abstract}
Background: Late presentation (LP), defined as a CD4 count $<350 / \mathrm{mm}^{3}$ or an AIDS-event at HIV-diagnosis, remains a significant problem across Europe. Linking cohort and surveillance data, we assessed the country-specific burden of LP during 2010-2016 and the occurrence of new AIDS events or deaths within 12 months of HIV-diagnosis believed to be attributable to LP.

Methods: Country-specific percentages of LP and AIDS-events/death rates (assessed with Poisson regression) observed in The Collaboration of Observational HIV Epidemiological Research Europe (COHERE) and EuroSIDA cohorts, were applied to new HIV-diagnoses reported to the European Centre for Disease Prevention and Control. The estimated number of LP in the whole population was then calculated, as was the number of excess AIDSevents/deaths in the first 12 months following HIV-diagnosis assumed to be attributable to LP (difference in estimated events between LP and non-LP).

Results: Thirty-nine thousand two hundred four persons were included from the COHERE and EuroSIDA cohorts, of whom 18,967 (48.4\%; 95\% Confidence Interval [CI] 47.9-48.9) were classified as LP, ranging from 36.9\% in Estonia $(95 \% \mathrm{Cl} 25.2-48.7)$ and Ukraine $(95 \% \mathrm{Cl} 30.0-43.8)$ to $64.2 \%$ in Poland $(95 \% \mathrm{Cl} 57.2-71.3)$. We estimated a total of $>$ 320,000 LP and 12,050 new AIDS-events/deaths attributable to LP during 2010-2016, with the highest estimated numbers of LP and excess AIDS-events/deaths in Eastern Europe. Country-level estimates of excess events ranged from 17 AIDS-events/deaths (95\%Cl 0-533) in Denmark to 10,357 (95\%Cl 7768-147,448) in Russia.

Conclusions: Across countries in Europe, the burden of LP was high, with the highest estimated number of LP and excess AIDS-events/deaths being in Eastern Europe. Effective strategies are needed to reduce LP and the attributable morbidity and mortality that could be potentially avoided.
\end{abstract}

Keywords: HIV, AIDS, Late presentation, Avoidable events, Eastern Europe, HIV testing

\section{Background}

Early HIV diagnosis and treatment are pivotal to maximizing individual and public health benefits of antiretroviral treatment (ART) [1,2]. Despite increased focus on testing and linkage to care in recent years [3], across Europe, an estimated $40-60 \%$ of people do not present for HIV care until their CD4 cell count has decreased

Correspondence: Kamilla.groenborg.laut.01@regionh.dk

https://www.eurosurveillance.org/ below 350 cells $/ \mathrm{mm} 3$ or they have experienced an AIDS defining disease [4-6]. These late presenters [7] suffer individual health consequences in terms of high morbidity and mortality, especially during the first year after testing HIV-positive [8-10]. Additionally, late presentation (LP) has public health consequences in terms of increased risk of onward transmission of HIV and increased health care costs [11-13].

(c) The Author(s). 2020 Open Access This article is licensed under a Creative Commons Attribution 4.0 International License, which permits use, sharing, adaptation, distribution and reproduction in any medium or format, as long as you give appropriate credit to the original author(s) and the source, provide a link to the Creative Commons licence, and indicate if changes were made. The images or other third party material in this article are included in the article's Creative Commons licence, unless indicated otherwise in a credit line to the material. If material is not included in the article's Creative Commons licence and your intended use is not permitted by statutory regulation or exceeds the permitted use, you will need to obtain permission directly from the copyright holder. To view a copy of this licence, visit http://creativecommons.org/licenses/by/4.0/ The Creative Commons Public Domain Dedication waiver (http://creativecommons.org/publicdomain/zero/1.0/) applies to the data made available in this article, unless otherwise stated in a credit line to the data. 
Many European countries have published data from cohort studies on prevalence and risk factors for LP [5, $8,14,15]$. Less is known about the absolute numbers of patients with LP in individual countries, and excess morbidity and mortality that could be potentially avoided by earlier diagnosis and treatment. This is especially true for countries in Eastern Europe, where surveillance of HIV-infection may be more complex $[16,17]$.

The European Centre for Disease Prevention and Control (ECDC) publishes annual summaries of HIV across Europe, which may be more complete than data from individual cohorts, but are limited by a lack of information on outcomes after HIV-diagnosis and by incomplete reporting $[15,18,19]$. In contrast, large cohort studies, such as The Collaboration of Observational HIV Epidemiological Research Europe (COHERE) and EuroSIDA, include participants with HIV from many cohorts and countries, and collect information on the prevalence and outcomes of LP $[20,21]$. Furthermore, the cohorts collect data from countries where surveillance data are limited. Linking surveillance data and cohort data, the aims of this study were therefore to estimate the burden of LP in 17 European countries, and to estimate the number of new AIDS-events or deaths in the 12 months following HIV-diagnosis that were believed to be attributable to LP.

\section{Methods}

\section{Patients}

We included participants from countries in the COHERE and EuroSIDA studies where at least 50 people presented for care during the study period. Regions were defined as in ECDC surveillance reports [15]. EuroSIDA holds the largest number of participants from Central (Poland) and Eastern European countries (Belarus, Estonia, Russia, Ukraine). Participants from these two regions were included from EuroSIDA and excluded from COHERE, to avoid duplicates. All people aged $\geq 16$ years, who presented for care (defined as earliest date of HIVdiagnosis, first clinic visit, or enrolment into the participating cohort) for the first time after 1st January 2010, were eligible for inclusion. The last merger of COHERE data was in 2015 and therefore patients from COHERE were included to $31 / 12 / 2014$. To increase the number of people included and thus ensure more precise estimates of LP in Central and Eastern Europe, we expanded the inclusion period to $01 / 01 / 2001-31 / 12 / 2016$ for participants included from EuroSIDA.

Participants were required to have at least one CD4 cell count measured within 6 months of HIV-diagnosis and were excluded if date of HIV-diagnosis or sex was missing. People were also excluded if there was evidence of an earlier HIV-diagnosis (CD4 cell count, AIDS diagnosis, or having started ART) more than 1 month before first clinic visit. Persons from EuroSIDA were additionally excluded if they had tested HIV-positive more than 12 months prior to enrolment in the cohort, to reduce survival bias. Finally, within COHERE, persons from the seroconverter cohorts were excluded, as in previous LPanalyses [8].

\section{Definitions}

Using the consensus definition, LP was defined as an HIV-diagnosis at a CD4 cell count below 350 cells $/ \mathrm{mm}^{3}$ or with an AIDS-defining event regardless of CD4 count in the 6 months following HIV-diagnosis [7]. Events were classified as AIDS using the 1993 Centers for Disease Control and Prevention clinical definition. A new event after HIV-diagnosis was defined as either death or a new AIDS-event occurring more than 30 days after HIV-diagnosis or subsequent to the AIDS-event used to classify a person as LP.

\section{Statistical analyses}

We used logistic regression to assess the change in LP over calendar time, adjusting for HIV transmission category, age, region of care, region of birth and delayed entry into care ( $>3$ months between HIV-diagnosis and first clinic visit). Multivariable linear regression was used to assess the change over time in CD4 cell count at HIV-diagnosis after adjustment for the variables listed above. Both analyses were performed separately for COHERE 2010-2014 and EuroSIDA 2001-2016. Estimates of the annual number of new HIV-diagnoses 2010-2016 were obtained from ECDC reports available online [15]. Estimates for Russia were also available online [22, 23].

We calculated the country-specific burden of LP, assuming that the percentages of LP observed in COHERE/EuroSIDA applied to all new HIV-diagnoses reported to ECDC/Russia, and that the rate of LP remained stable over the study period [5]. The 95\% confidence interval (CI) for the percentage with LP was used to provide lower and upper bounds for these estimates.

We subsequently calculated the country-specific estimates of new AIDS-events/deaths within the first year following HIV-diagnosis that could be attributable to LP. First, the event rates in COHERE/EuroSIDA within 12 months of HIV-diagnosis were calculated separately for those with and without LP and were compared in Poisson regression adjusting for age and HIV transmission category. The mean follow-up time per country was also assessed. We then applied the country-specific rate of new AIDS-events/death of non-LP to the total reported number of persons diagnosed HIV-positive (from ECDC/Russia), assuming that the follow-up time within the first 12 months and the proportion of LP were the same as observed in the cohorts. The adjusted incidence rate ratio and $95 \% \mathrm{CI}$ were applied to this number of 
non-LP to estimate the number of LP. The number of AIDS-events/deaths assumed to be attributable to LP, was calculated as the difference in event rates between LP and non-LP within each country. Belarus, Estonia, Poland, Russia and Ukraine reported no events in the first 12 months among non-LP, and for these countries, the average event rate and adjusted incidence rate ratio for the whole population (i.e. in all 17 countries) combined was assumed to apply. To account for differences in countries' population size, excess events per 1 million inhabitants were calculated using population estimates from Eurostat [24].

\section{Sensitivity analyses}

In sensitivity analyses, we assessed the generalisability of our estimates of LP and AIDS-events/deaths to all diagnosed HIV-positive in each country. Data from The European Surveillance System (TESSy) [25], provided by the ECDC, were used to weight cohort data to reproduce key demographic characteristics of all diagnosed HIVpositive in the study period. In brief, we compared key characteristics (age, sex and HIV transmission category) in our study population with TESSy data and assigned weights to either increase or decrease different demographic groups in our study [26]. For example, if $15 \%$ of participants in the UK were male, infected via injecting drug use and above 50 years, but this proportion using TESSy data was $20 \%$, this group of individuals was under-represented in COHERE/EuroSIDA, and thus the number of LP or AIDS-events/deaths in this group was weighted upwards by $33 \%(0.2 / 0.15)$. Estimates from TESSy were not available for Estonia, Russia and Ukraine, and here we used the unweighted proportion estimated from COHERE/EuroSIDA. We repeated the analyses excluding events where AIDS occurred within the first 6 months, to reduce any potential bias from persons presenting with AIDS and being diagnosed with a new AIDS defining illness shortly thereafter.

\section{Results}

Thirty-nine thousand two hundred four persons were included from the COHERE and EuroSIDA cohorts and overall, around half ( $n=18,967,48.4 \%$; $95 \%$ CI $47.9-48.9)$ were classified as LP (Table 1). The majority lived in Western Europe $(n=38,511,98.2 \%)$, were born in Europe $(n=25,746,65.0 \%)$, were men who had sex with men $(n=20,061,51.3 \%)$, had a median age of 37 years (interquartile range [IQR] 29-45) and CD4 cell count at diagnosis of 365 cells $/ \mathrm{mm}^{3}$ (IQR 186-553). The majority of the LPs (77.5\%) were classified as LP based on having a CD4 $<350$ cells $/ \mathrm{mm}^{3}$ (Table 2). The proportion with LP did not change significantly over time either in COHERE (2010-2014) or EuroSIDA (2001-2016). The adjusted odds of LP per later year of HIV diagnosis was
0.98 (95\% CI 0.97-1.00 [ $p=0.058])$ in COHERE and 0.99 (95\%CI 0.95-1.04 $[p=0.79])$ in EuroSIDA. Likewise, the CD4 cell count at HIV-diagnosis did not change significantly over time: the change in CD4 cell count at diagnosis was 1.30 cells $/ \mathrm{mm}^{3}$ per year $(95 \% \mathrm{CI}-0.80-3.40$ $[p=0.23])$ in COHERE and $-0.54 / \mathrm{mm}^{3}$ per year $(95 \% \mathrm{CI}$ $-6.05-5.00[p=0.85])$ in EuroSIDA.

\section{Estimated burden of LP}

Table 2 shows the percentage of LP within COHERE/ EuroSIDA in each country where more than 50 study participants presented for care during the study period. The percentage of LP varied considerably from $36.9 \%$ in Estonia (95\%CI 25.2-48.7) and Ukraine (95\%CI 30.0$43.8)$ to $64.2 \%$ in Poland (95\%CI $57.2-71.3$ ). The estimated number of LP in the whole country in the period is also shown, assuming that the rates of LP observed in COHERE and EuroSIDA applied to all diagnosed HIVpositive in the whole country during 2010-2016. For example, in Russia, estimates suggest 551,251 persons were diagnosed HIV-positive during 2010-2016. If the rate of LP seen in this study (45.2\%) applied throughout Russia, there would be a total of 249,375 LP over the same period (95\%CI 207,886-290,865).

On the regional level, if the rates of LP observed in COHERE/EuroSIDA were assumed to apply throughout the region, we estimated that 102,203 people in Western Europe (95\%CI 101,148-103,257), 20,660 in Central Europe $(95 \%$ CI $18,402-22,918)$ and 370,472 (95\%CI 327 , 912-413,032) in Eastern Europe would have presented late between 2010 and 2016 (Table 2).

\section{Estimated excess AIDS-events/deaths}

The rates of new AIDS-events/deaths within 1 year following HIV-diagnosis, stratified by LP and non-LP are given in Table 3 , in addition to the adjusted ratio between incidence rates in LP and non-LP. Overall, LP was associated with a 9-fold higher incidence of AIDSevents/deaths within 1 year of HIV-diagnosis (adjusted incidence rate ratio 9.3 [95\%CI 7.2-12.0]), compared to non-LP. However, there was considerable heterogeneity between countries, ranging from a more than 15 -fold higher incidence of new AIDS-events/death among LP in Belgium, Spain and France to a 4-5-fold difference in Denmark, Sweden, Switzerland and the UK. Some countries (Belarus, Estonia, Poland, Russia, Ukraine) had no new AIDS-events/ death events reported among non-LP. For these countries, the average incidence $(4.2$ [95\% CI 3.2-5.2]) as well as the average adjusted incidence rate ratio $(9.3$ [95\%CI 7.2-11.9]) for the whole study population were assumed to apply.

Excess AIDS-events/deaths attributable to LP during 2010-2016 are also shown in Table 3, assuming that event rates among LP would be the same as in non-LP if they had been diagnosed and treated similarly. For 
Table 1 Characteristics of included patients from COHERE 2010-2014 and EuroSIDA 2001-2016

\begin{tabular}{|c|c|c|}
\hline & $\begin{array}{l}\text { All } \\
\mathrm{n}(\% \text { of all) }\end{array}$ & $\begin{array}{l}\text { Late presenters } \\
\mathrm{n}(\% \text { of } L P)^{\mathrm{b}}\end{array}$ \\
\hline Total number of people included & $39,204(100)$ & $18,967(48.4)$ \\
\hline \multicolumn{3}{|l|}{ Mode of infection } \\
\hline Sex between men & $20,061(51.2)$ & $7712(38.4)$ \\
\hline Sex between men and women - men & $6262(16.0)$ & $3915(62.5)$ \\
\hline Sex between men and women - women & $6400(16.3)$ & $3529(55.1)$ \\
\hline Injecting drug use - men & $1293(3.3)$ & $753(58.2)$ \\
\hline Injecting drug use - men & $401(1.0)$ & $165(41.2)$ \\
\hline Men other & $3304(8.4)$ & $2006(60.7)$ \\
\hline Women other & $1483(3.8)$ & $887(59.8)$ \\
\hline \multicolumn{3}{|l|}{ Region of residence } \\
\hline West & $38,511(98.2)$ & $18,629(48.4)$ \\
\hline Central (EuroSIDA only) & $179(0.5)$ & $115(64.2)$ \\
\hline East (EuroSIDA only) & $514(1.3)$ & $223(43.4)$ \\
\hline \multicolumn{3}{|l|}{ Region of birth } \\
\hline Europe & $25,746(65.0)$ & $11,773(46.2)$ \\
\hline Africa & $3666(9.4)$ & $2345(64.0)$ \\
\hline Other & $3670(9.4)$ & $2005(54.6)$ \\
\hline Unknown & $6392(16.3)$ & $2844(44.5)$ \\
\hline \multicolumn{3}{|l|}{ Cohort } \\
\hline COHERE 2010-2014 & $38,511(98.2)$ & $18,629(48.4)$ \\
\hline \multirow[t]{2}{*}{ EuroSIDA 2001-2016 } & $693(1.8)$ & $338(48.8)$ \\
\hline & median (IQR) & median (IQR) \\
\hline Age (years) & $37(29-45)$ & $39(32-48)$ \\
\hline CD4 cell count at entry into COHERE/EuroSIDA $\left(/ \mathrm{mm}^{3}\right)$ & $365(186-553)$ & $180(70-272)$ \\
\hline Baselinet (month/year) & 10/2011 (11/2010-11/2012) & 09/2011 (11/2010-11/2012) \\
\hline
\end{tabular}

Countries included from EuroSIDA: Central Europe: Poland. Eastern Europe: Belarus, Estonia, Russia, Ukraine. † Baseline was defined as the earliest of positive HIV test, first study visit or cohort enrolment. ${ }^{a}$ percentage is a column percentage. ${ }^{b}$ percentage is a row percentage

example, if the event rate observed in the cohorts in the first year following diagnosis applied to all diagnosed HIV-positive in Austria, with a mean follow-up in the first year after HIV-diagnosis of 0.89 years, during 20102016 we would have expected to observe 49 AIDSevents/deaths in LP and 5 in non-LP in the first year after diagnosis, a difference of 44 events (95\%CI 7-415). The highest burden of excess AIDS-events/deaths during 2010-2016 was expected in Russia ( $n=10,357$ [95\%CI 7768-147,478]), and the lowest in Denmark, Sweden and Switzerland.

Table 3 also gives regional estimates, showing that the incidence of AIDS-events/death in non-LP in Western Europe, where there were most data, was 4.3/1000 PYFU (95\%CI 3.3-5.4), and in LP was 51.5 (95\%CI 47.9-55.2). Within Western Europe, the number of estimated excess AIDS-events/deaths in 2010-2016 attributable to LP was 3030 (95\%CI 2273-19,934), in Central Europe 407
(95\%CI 306-2355) and in Eastern Europe it was 14,597 (95\%CI 10,947-109,680).

\section{Representativeness of EuroSIDA and COHERE}

When weights were applied to COHERE/EuroSIDA data to match the key demographic characteristics of the TESSy population, in general our data underestimated LP (Fig. 1). We could not include Estonia, Russia and Ukraine in this sensitivity analysis due to a lack of data from either COHERE/EuroSIDA or TESSy. The overall estimate of LP in the cohorts was $48.4 \%$ (95\%CI 47.9-48.9), which increased slightly to $49.2 \%$ (95\%CI 48.7-49.7), after accounting for differences in age, sex and HIV transmission category between COHERE/EuroSIDA and the TESSy reference population. Austria, Germany and Italy had a lower percentage of LP after weighting; all other countries had a higher percentage of LP after comparison with TESSy data, with the biggest increase in Poland (9.1\%). 
Table 2 Estimated burden of late presentation by country and region 2010-2016

\begin{tabular}{|c|c|c|c|c|}
\hline \multirow[b]{3}{*}{ Country } & \multicolumn{2}{|c|}{ Late presenters in COHERE/EuroSIDA } & \multirow{2}{*}{$\begin{array}{l}\text { Total number diagnosed } \\
\text { HIV-positive } 2010-2016^{a}\end{array}$} & \multirow{2}{*}{$\begin{array}{l}\text { Estimated number of LP in } \\
\text { the whole country 2010-2016 }\end{array}$} \\
\hline & $\begin{array}{l}\text { Percentage with CD4 } \\
<350 / \mathrm{mm}^{3} \text { and/or AIDS }\end{array}$ & $\begin{array}{l}\text { Percentage of LP with CD4 }<350 / \mathrm{mm}^{3} \\
\text { and no AIDS }\end{array}$ & & \\
\hline & $\%$ of all $(95 \% \mathrm{Cl})$ & $\%$ of LP & $n$ & n $(95 \% \mathrm{Cl})$ \\
\hline Austria & $48.4(45.1-51.6)$ & 71.5 & 2200 & $1064(993-1135)$ \\
\hline Belarus & $57.4(47.5-67.4)$ & 79.6 & 11,528 & $6622(5470-7775)$ \\
\hline Belgium & $42.3(38.8-45.8)$ & 78.8 & 7675 & $3247(2975-3519)$ \\
\hline Denmark & $52.8(48.9-56.6)$ & 74.3 & 1755 & $926(858-994)$ \\
\hline Estonia & $36.9(25.2-48.7)$ & 100.0 & 2172 & $802(547-1057)$ \\
\hline France & $48.6(47.1-50.0)$ & 76.6 & 41,148 & $19,979(19,380-20,578)$ \\
\hline Germany & $56.8(55.2-58.4)$ & 66.1 & 22,186 & $12,604(12,253-12,954)$ \\
\hline Greece & $47.5(45.2-49.7)$ & 86.6 & 5862 & $2782(2648-2916)$ \\
\hline Italy & $52.0(50.8-53.3)$ & 81.9 & 26,691 & $13,882(13,551-14,213)$ \\
\hline The Netherlands & $44.6(43.2-46.0)$ & 69.1 & 7206 & $3213(3111-3316)$ \\
\hline Poland & $64.2(57.2-71.3)$ & 70.4 & 8268 & $5312(4731-5892)$ \\
\hline Russia & $45.2(37.7-52.8)$ & 86.8 & 551,251 & $249,375(207,886-290,865)$ \\
\hline Spain & $44.3(43.2-45.5)$ & 76.1 & 26,917 & $11,935(11,624-12,245)$ \\
\hline Sweden & $56.7(54.5-59.0)$ & 81.1 & 3128 & $1774(1703-1845)$ \\
\hline Switzerland & $53.0(49.9-56.1)$ & 79.8 & 3961 & $2100(1977-2222)$ \\
\hline United Kingdom & $43.5(42.1-44.8)$ & 84.0 & 42,292 & $18,393(17,824-18,963)$ \\
\hline Ukraine & $36.9(30.0-43.8)$ & 88.4 & 111,731 & $41,227(33,500-48,954)$ \\
\hline \multicolumn{5}{|l|}{ Region } \\
\hline Central $^{\mathrm{b}}$ & $64.2(57.2-71.3)$ & & 32,158 & $20,660(18,402-22,918)$ \\
\hline East $^{\mathrm{b}}$ & $47.1(41.7-52.5)$ & & 786,651 & $370,472(327,912-413,032)$ \\
\hline West $^{\mathrm{b}}$ & $48.4(47.9-48.9)$ & & 211,280 & $102,203(101,148-103,257)$ \\
\hline
\end{tabular}

${ }^{\mathrm{a} A s}$ reported by ECDC, except for Russia, as described in text. ${ }^{\mathrm{b}}$ As defined by ECDC. Regional estimates are not summations of those estimated for each country. Cl Confidence Interval, LP Late Presentation

The weighted percentage of LP was then used to reestimate the burden of LP and AIDS-events/deaths in the 12 months following HIV-diagnosis in 2010-2016. The estimated total number of LP rose marginally from $320,898(95 \% \mathrm{CI} 286,173-355,624)$ to 323,286 (95\%CI 288,579-357,993), and excess AIDS-events/deaths among LP increased from 12,050 (95\%CI 5064-18,348) to 12 , 164 (95\%CI 5156-18,510) events.

\section{Effect of population size and new AIDS-events}

As shown in Fig. 2, differences between countries remained when differences in population size were accounted for. For example, the highest number of excess AIDS-events/deaths attributable to LP during 2010-2016 was in Russia (72 events per 1 million inhabitants), and the lowest was in Sweden (2 events per 1 million inhabitants). Excluding those who developed AIDS within 6 months after HIV-diagnosis reduced the estimated excess events attributable to LP, but differences between countries remained, with the highest burden of excess morbidity and mortality observed in countries in Eastern Europe.

\section{Discussion}

We aimed to quantify the burden of late presentation of HIV, and estimated that, among those diagnosed HIVpositive in 2010-2016, approximately half - equivalent to more than 320,000 people - were LP. We estimated that approximately 3030, 407 and 14,597 AIDS-events/ deaths in Western, Central and Eastern Europe, respectively, were attributable to LP and could potentially have been avoided by earlier diagnosis and the concomitant potential for starting ART earlier. Our figures highlight that there is still a need to improve efforts to ensure timely diagnosis of HIV, and to reduce the health consequences of LP.

Since 2010 there have been many innovative approaches to increase and target HIV testing, including home testing, community-based testing, and indicatorguided testing [27-31]. Furthermore, an increase in the number of tests performed across Europe has been 
Table 3 Estimated excess AIDS/death in the first year after HIV-diagnosis by country and region 2010-2016

\begin{tabular}{|c|c|c|c|c|c|c|}
\hline \multirow{3}{*}{ Country } & \multirow[b]{2}{*}{$\begin{array}{l}\text { Number included } \\
\text { from COHERE/ } \\
\text { EuroSIDA }\end{array}$} & \multirow[b]{2}{*}{$\begin{array}{l}\text { Mean follow-up in } \\
\text { COHERE/EuroSIDA } \\
\text { in the first } \\
12 \text { months following } \\
\text { HIV-diagnosis }\end{array}$} & \multirow[b]{2}{*}{$\begin{array}{l}\text { Non-late presenters } \\
\text { 1-year incidence } \\
\text { of AIDS/deaths } \\
\text { observed in } \\
\text { COHERE/EuroSIDA }\end{array}$} & \multirow{2}{*}{$\begin{array}{l}\text { Late presenters } \\
\text { 1-year incidence } \\
\text { of AIDS/deaths } \\
\text { observed in } \\
\text { COHERE/EuroSIDA a }\end{array}$} & \multicolumn{2}{|c|}{ Difference LP versus non-LP } \\
\hline & & & & & $\begin{array}{l}\text { Adjusted ratio } \\
\text { of } 1 \text {-year incidence } \\
\text { of AIDS/deaths } \\
\text { between LP and } \\
\text { non-LP }\end{array}$ & $\begin{array}{l}\text { Estimated excess } \\
\text { AIDS/deaths } \\
\text { attributable to LP } \\
\text { (difference LP - } \\
\text { non-LP) })^{d} \text { 2010-2016 }\end{array}$ \\
\hline & $n$ & mean PYFU & $\begin{array}{l}\text { IR/1000 PYFU } \\
(95 \% \mathrm{Cl})\end{array}$ & $\begin{array}{l}\text { IR/1000 PYFU } \\
(95 \% \mathrm{Cl})\end{array}$ & alRR $(95 \% C l)$ & n $(95 \% \mathrm{Cl})$ \\
\hline Austria & 920 & 0.89 & $4.7(0.6-17.0)$ & $63.3(38.5-88.1)$ & $10.20(2.4-43.3)$ & $44(7-415)$ \\
\hline Belarus $^{c}$ & 94 & 0.98 & $4.2(3.2-5.2)$ & $37.7(4.6-136.1)$ & $9.3(7.2-11.9)$ & $169(127-2754)$ \\
\hline Belgium & 747 & 0.84 & $2.8(0.1-15.4)$ & $79.4(45.4-113.3)$ & $25.4(3.4-190.9)$ & $250(24-1152)$ \\
\hline Denmark & 635 & 0.83 & $7.9(1.0-28.5)$ & $61.8(36.9-98.9)$ & $4.2(0.9-18.4)$ & $17(0-533)$ \\
\hline Estonia $^{c}$ & 65 & 0.98 & $4.2(3.2-5.2)$ & $86.6(10.5-312.7)$ & $9.3(7.2-11.9)$ & $47(35-1768)$ \\
\hline France & 4531 & 0.68 & $2.5(0.7-6.5)$ & $59.8(47.4-72.2)$ & $19.2(7.0-52.7)$ & $661(218-2581)$ \\
\hline Germany & 3774 & 0.83 & $4.4(1.6-9.6)$ & $58.6(47.3-69.9)$ & $11.1(4.8-25.4)$ & $353(134-2408)$ \\
\hline Greece & 1829 & 0.82 & $5.0(1.4-12.8)$ & $43.0(27.6-58.5)$ & $7.5(2.6-21.5)$ & $82(20-724)$ \\
\hline Italy & 6241 & 0.80 & $5.1(2.5-8.8)$ & $44.8(36.7-53.0)$ & $6.6(3.6-11.9)$ & $286(134-2674)$ \\
\hline The Netherlands & 4680 & 0.84 & $5.4(2.8-9.5)$ & $69.8(57.4-82.1)$ & $9.9(5.4-18.0)$ & $163(81-1490)$ \\
\hline Poland ${ }^{c}$ & 179 & 0.99 & $4.2(3.2-5.2)$ & $8.8(0.2-48.9)$ & $9.3(7.2-11.9)$ & $102(77-591)$ \\
\hline Russiac & 168 & 0.98 & $4.2(3.2-5.2)$ & $40.7(8.4-118.9)$ & $9.3(7.2-11.9)$ & $10,357(7768-147,448)$ \\
\hline Spain & 7118 & 0.78 & $1.9(0.7-4.2)$ & $52.9(43.8-62.0)$ & $18.9(8.3-43.2)$ & $404(165-1377)$ \\
\hline Sweden & 1830 & 0.81 & $7.9(2.6-18.5)$ & $32.7(20.6-44.9)$ & $3.7(1.4-9.7)$ & $24(4-382)$ \\
\hline Switzerland & 998 & 0.82 & $5.4(0.7-19.3)$ & $25.0(12.5-44.6)$ & $5.2(1.0-25.7)$ & $34(0-355)$ \\
\hline $\begin{array}{l}\text { United } \\
\text { Kingdom }\end{array}$ & 5208 & 0.72 & $5.4(2.7-9.7)$ & $37.6(28.4-46.9)$ & $5.1(2.7-9.9)$ & $382(153-4252)$ \\
\hline Ukraine $e^{c}$ & 187 & 0.98 & $4.2(3.2-5.2)$ & $59.2(16.1-151.6)$ & $9.3(7.2-11.9)$ & $2424(1818-44,080)$ \\
\hline \multicolumn{7}{|l|}{ Region $^{\mathrm{e}}$} \\
\hline Central $^{c}$ & 179 & 0.99 & $4.3(3.3-5.4)$ & $8.8(0.2-48.9)$ & $9.3(7.2-11.9)$ & 407 (306-2355) \\
\hline East $^{c}$ & 327 & 0.98 & $4.3(3.3-5.4)$ & $36.2(18.7-63.2)$ & $9.3(7.2-11.9)$ & $\begin{array}{l}14,597(10,947-109 \\
680)\end{array}$ \\
\hline West & 38,511 & 0.79 & $4.3(3.3-5.4)$ & $51.5(47.9-55.2)$ & $9.2(7.2-11.9)$ & $3030(2273-19,934)$ \\
\hline
\end{tabular}

${ }^{a}$ Estimated number of events among LP or non-LP was estimated by applying event rates from COHERE/EuroSIDA to the total number diagnosed HIV-positive in the whole country (incidence rate (PYFU) $x$ mean follow-up (PYFU) $x$ number of LP or non-LP in the whole country). ${ }^{b}$ Adjusted for age, sex and HIV exposure group. 'In Belarus, Estonia, Poland, Russia and Ukraine there were no registered events among non-LP in EuroSIDA/COHERE. The IR and the aIRR given for these countries are the averages for all countries combined. ${ }^{d}$ Excess events were estimated as clinical events in LP compared to non-LP. ${ }^{e}$ As defined by ECDC. Regional estimates are not summations of those estimated for each country. alRR Adjusted Incidence Rate Ratio, $C I$ Confidence interval, $I R$ Incidence Rate, $L P$ Late Presentation, PYFU Person years of follow-up

described [15]. Despite these initiatives, we found no evidence of a significant reduction in LP since 2010, which supports recent surveillance data that show no signs of decline in LP over the past decade [15]. Furthermore, the number of new HIV infections across Europe, in general, does not appear to be decreasing, and even shows signs of increasing among some subpopulations $[32,33]$. Importantly, the steady increase in new infections in Eastern Europe is of particular concern [15, 34].

The pattern of LP varied across countries and regions. Reasons for LP are diverse, and include different testing strategies, challenges to identify and effectively reach those requiring a test, missed opportunities to offer a test, low self-perceived risk or limited knowledge about risk factors for HIV infection, fear of the implications of a positive test, perceived stigma and legal and regulatory barriers to testing and treatment [14, 27, 35-39]. There is a need for a comprehensive and holistic approach in order to address these known causes for LP. An additional barrier to timely treatment is delayed entry into care following diagnosis, although studies have shown that such delay accounted for less than $10 \%$ of LP $[8$, 36]. In our study the vast majority were classified as LP based on their CD4 cell count rather than an AIDSevent, which may indicate a need to increase testing based on indicator diseases as well as among individuals belonging to high prevalence populations. Furthermore, our estimates of the burden of LP were marginally 


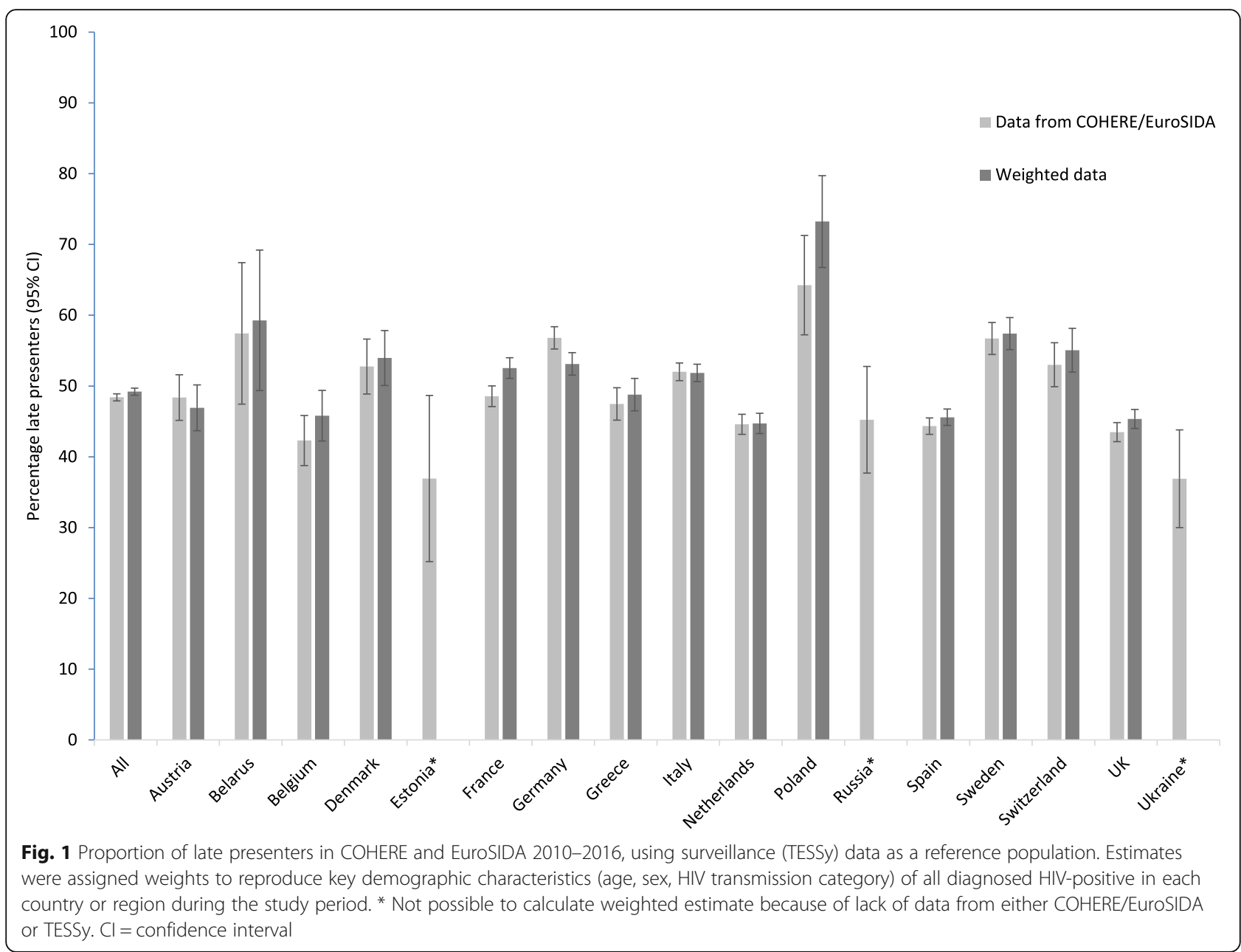

higher when the representativeness of the data was accounted for, demonstrating that some populations may not be fully represented in our cohorts [26]. Our figures thus highlight the urgent need to more effectively target testing interventions to these populations before they present late.

This study extends our previous work by applying estimates of LP from cohorts to surveillance data, which may lack longitudinal follow-up and data on clinical outcomes. This allowed us to estimate the country-specific burden of LP and to provide estimates of excess morbidity and mortality occurring in the first year following HIV-diagnosis, attributable to LP. We estimate that during 2010-2016 a total 12,050 excess AIDS-events/deaths within the first year of HIV-diagnosis could potentially have been avoided if late presenters had been diagnosed with HIV and started treatment similar to those diagnosed early in COHERE and EuroSIDA. This likely represents an under-estimate of the clinical benefit of starting ART earlier. Our findings are based on cohort data in years when a large proportion of patients did not start ART until their CD4 cell count was below 350 cells $/ \mathrm{mm}^{3}$, and largely before the results of the INSI GHT START study led to changes in clinical management in Europe [1]. This means that potentially even more events could have been avoided if all had been diagnosed and started treatment promptly $[8,10,40]$.

We compared event rates among LP and non-LP followed at the same clinics within the same country. This allowed us to estimate potentially avoidable AIDSevents/deaths without taking into consideration variation in life-expectancy, health care organization, reporting practices and other factors that may affect betweencountry comparisons. We were, however, surprised that the observed event rates in countries in Eastern Europe were smaller than in some other countries $[15,41]$. It is likely that individuals in our cohorts represent a subset of the whole HIV-diagnosed population with better outcomes. Participants in COHERE and EuroSIDA are engaged in clinical care, and we may therefore exclude people who are not under regular follow-up or those who do not survive long enough to be diagnosed and included in the cohorts. Furthermore, low event rates may cover incomplete reporting, despite our efforts to ensure 


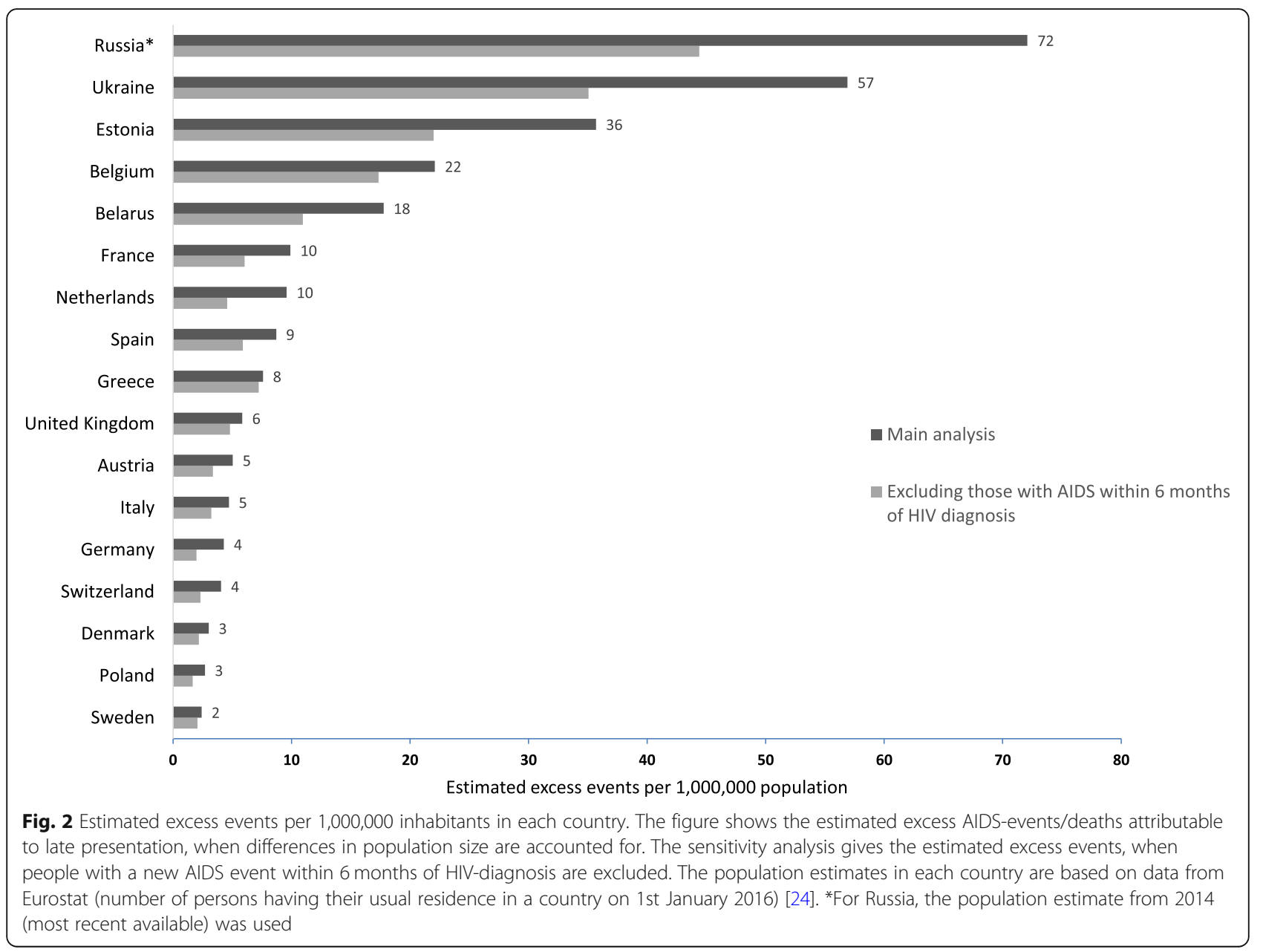

high data quality. Also, we only considered new events within 12 months after HIV-diagnosis, and our analyses do not account for potentially avoidable events before or at HIV-diagnosis. Thus, our numbers probably underestimate the actual number of potentially avoidable AIDS-events/deaths.

A strength of this study is the country-level estimates of LP from seventeen countries across Europe, including countries in Eastern Europe where data are limited [42]. However, despite the large size of the COHERE and EuroSIDA cohorts, we were only able to include data from five countries outside Western Europe and we had comparatively small numbers from those countries. The limitations of extrapolating event rates from relatively few participants to the whole HIV-diagnosed population should be kept in mind when interpreting results. Further, for Russia there were no official statistics on the number of new HIV-diagnoses and we used estimates from sources available online. Increasing the availability and robustness of data from Eastern Europe remains an urgent priority.
For our main analysis, we assumed that persons in COHERE/EuroSIDA were representative of all HIVdiagnosed persons. In sensitivity analyses, we then used TESSy data to reproduce the demographic characteristics (age, sex and HIV transmission category) of the whole HIV-diagnosed population. Estimates were similar, but the burden of LP and excess AIDSevents/deaths attributable to LP were slightly higher using this weighted analysis. We chose not to use additional factors, such as ethnicity or CD4 count at presentation, because the sample size used for weighting within additional groups would have been small in some countries. Further, we were not able to use this sensitivity analysis in Estonia, Russia or Ukraine due to lack of data in COHERE/EuroSIDA and/or TESSy. Although our analyses indicate that our cohorts capture a representative sample of the whole HIV-diagnosed population, sites in EuroSIDA and COHERE are not selected at random and may not be representative of all clinics across the included countries. Finally, a limitation of our study is that different 
inclusion periods were used for COHERE (20102014) and EuroSIDA (2001-2016). This was done to increase the number of people included, and thus the robustness of estimates from Central and Eastern Europe. While the LP-rate has not changed significantly over the past decade, the awareness of timely ART, the components of ART-regimens and the overall quality of care may have improved over time. Thus, AIDS-events/death event rates from early in the study period may be higher than in recent years, which would tend to overestimate the number of potentially avoidable events.

The recent introduction of pre-exposure prophylaxis (PrEP) may be expected to reduce HIV transmission among some high-prevalence groups. However, we may speculate that the use of PrEP concentrates on people that have a high awareness of HIV and may be expected to test at a relatively early stage of infection. If so, PrEP may reduce HIV transmission, but not among those at highest risk for presenting late, thus leading to an overall increase in the percentage with LP in coming years.

\section{Conclusions}

We found that LP remains a significant problem across Europe and translates into a substantial burden of morbidity and mortality, which could potentially be avoided by earlier diagnosis and treatment for HIV. An innovative and holistic approach spanning the HIV prevention, diagnosis, treatment and care continuum is needed to reduce the burden of HIV-related morbidity and mortality, which is potentially avoidable if people access timely ART.

\section{Abbreviations}

AIDS: Acquired immunodeficiency syndrome; ART: Antiretroviral therapy; CD4: CD4 receptor positive T-lymphocyte cell; Cl: Confidence interval; COHERE: Collaboration of observational HIV epidemiological research Europe; ECDC: The European centre for disease prevention and control; EuroSIDA: Is not an acronym; HIV: Human immunodeficiency virus; IQR: Interquartile range; LP: Late presentation; PrEP: Pre-exposure prophylaxis; PYFU: Person years of follow-up; TESSy: The European Surveillance System

\footnotetext{
Acknowledgements

The Late Presentation Working Groups in EuroSIDA and COHERE: Andrea Antinori, Barbara Bartmeyer, Marek Beniowski, Fabrice Bonnet, Johanna Brännström, Jordi Casabona, Antonella Castagna, Genevieve Chene, Dominique Costagliola, Antonella d'Arminio Monforte, Julia Del Amo Valero, Stephane De Wit, Gerd Faetkenheuer, Hansjakob Furrer, Jacek Gasiorowski, Corinne Jadand, Ole Kirk, Kamilla Grønborg Laut, Mario Lazanas, Ignacio Suarez-Lozano, Jens Lundgren, Julia Mikhalik, Amanda Mocroft, Santiago Moreno, Cristina Mussini, Niels Obel, Dzmitry Paduta, Dorthe Raben, Peter Reiss, Andrew Riordan, Caroline Sabin, Jelena Smidt, Carlo Torti, Tatiana Trofimova, Anna Vassilenko, Marta Vasylyev, Josiane Warszwski, Linda Wittkop, Alexei Yakovlev, Robert Zangerle.

The EuroSIDA study group may be found at: https://chip.dk/Studies/ EuroSIDA/Study-group

The COHERE acknowledgement appendix may be found at: http://www. cohere.org/Acknowledgements

The views and opinions of the authors expressed herein do not necessarily state or reflect those of ECDC. The accuracy of the authors' statistical analysis
}

and the findings they report are not the responsibility of ECDC. ECDC is not responsible for conclusions or opinions drawn from the data provided. ECDC is not responsible for the correctness of the data and for data management, data merging and data collation after provision of the data. ECDC shall not be held liable for improper or incorrect use of the data.

\section{Authors' contributions}

$A M, J L$ and OK proposed and developed the project. AM carried out the statistical analyses. KGL and AM drafted the article. AA, BB, MB, FB, JB, JC, AC, GC, DC, AAM, JDAV, SDW, GF, HF, JG, CJ, OK, KGL, ML, ISL, JL, JM, AM, SM, $C M, N O, D P, D R, P R, A R, C S, J S, C T, T T, A V, M V, J W, L W, A Y$ and $R Z$ contributed to the data analysis and interpretation of results. $A A, B B, M B, F B$, $J B, J C, A C, G C, D C, A A M, J D A V, S D W, G F, H F, J G, C J, O K, K G L, M L, I S L, J L, J M$, $A M, S M, C M, N O, D P, D R, P R, A R, C S, J S, C T, T T, A V, M V, J W, L W, A Y$ and $R Z$ have read and approved the manuscript.

\section{Funding}

EuroSIDA has received funding from ViiV Healthcare LLC, Janssen Scientific Affairs, Janssen R\&D, Bristol-Myers Squibb Company, Merck Sharp \& Dohme Corp, Gilead Sciences and the European Union's Seventh Framework Programme for research, technological development and demonstration under EuroCoord grant agreement $n^{\circ} 260694$. The participation of centres from Switzerland has been supported by The Swiss National Science Foundation (Grant 148522). The study is also supported by a grant [grant number DNRF126] from the Danish National Research Foundation and by the International Cohort Consortium of Infectious Disease (RESPOND).

The COHERE study group has received unrestricted funding from: Agence Nationale de Recherches sur le SIDA et les Hépatites Virales (ANRS), France; HIV Monitoring Foundation, The Netherlands; and the Augustinus Foundation, Denmark. The research leading to these results has received funding from the European Union Seventh Framework Programme (FP7) 2007-2013) under EuroCoord grant agreement no. 260694. A list of the funders of the participating cohorts can be found at www.cohere.org. The study sponsors had no role in the design of the study, the collection, analysis and interpretation of data, the writing of the report or the decision to submit the paper for publication.

\section{Availability of data and materials}

The EuroSIDA, COHERE and TESSy databases contain person-sensitive information and are therefore not publicly available, but are available from the corresponding author on reasonable request.

EUroSIDA.

The EuroSIDA Steering Committee encourages the submission of concepts for research proposals. Concepts can be submitted for review using an online research concept available at: https://chip.dk/Studies/EuroSIDA/ Submit-research-concept. A submitted research concept will be evaluated by the Steering Committee for scientific relevance, design, feasibility and overlap with already approved projects. Upon completion of the review, feedback will be provided to the proposer(s). In some circumstances, a revision of the concept may be requested. If approved, a writing group will be established. Details on the EuroSIDA study can be accessed at https:// chip.dk/Studies/EuroSIDA/About, where all relevant documents are available (study protocol, data collection, presentations, publications etc.). COHERE.

The last merger of COHERE data was in 2015 and COHERE no longer collects new data. However, any researcher wishing to use COHERE data to conduct a project can download a COHERE Project Proposal Form and a Data Specification Form available at http://www.cohere.org/Projects. Proposals from external investigators will undergo the same rigorous scrutiny as those from investigators within the study group; details are outlined in the COHERE Manual of Operations at http://www.cohere.org/.

TESSY.

The European Surveillance System (TESSy) is coordinated by the European Centre for Disease Prevention and Control. Researchers may request to get access to subsets of data by contacting the TESSy data access team, as described at: https://www.ecdc.europa.eu/en/publications-data/europeansurveillance-system-tessy. Access to aggregated published data is unrestricted and available at https://atlas.ecdc.europa.eu/public/index.aspx. 


\section{Ethics approval and consent to participate}

Appropriate local approval of the study and informed consent from participants are obtained according to local and/or national regulations in countries participating in the EurOSIDA and COHERE studies. The principal investigator at each collaborating site in EuroSIDA or the individual cohort in COHERE are responsible for obtaining and maintaining this/these approval(s) at all times.

A sample informed written consent form from EuroSIDA may be found at https://www.chip.dk/Studies/EuroSIDA/Study-documents. In EuroSIDA, if a written consent is not necessary according to local regulations, a participating site must have a signed Declaration of Absence of Ethics Approval. The Danish EuroSIDA approval (EuroSIDA coordinating centre located in Copenhagen, Denmark) applicable for this study was granted on 30 June 2014 with journal no. H-3-2012-049 by the Research Ethics Committee for the Capital Region of Denmark.

For COHERE, details on ethics committee approval, informed consent and confidentiality of data are described in the manual of operation available at http://www.cohere.org/Study-Documents/Manual-of-Operations-Appendices. Each participating cohort have signed a data protection agreement and data was collected according to the European Community Directive 95/46/EC on the protection of the individuals with regards to the processing of personal data and on the movement of such data and to the regulation transposing this Directive in the cohort's own country.

For TESSy, data are collected and submitted under the applicable national personal data protection law by TESSy users, as described in the Specific Privacy Statement: https://www.ecdc.europa.eu/sites/default/files/documents/ TESSy-specific-privacy-statement-August-2018.pdf.

\section{Consent for publication}

Not applicable.

\section{Competing interests}

All authors declare no conflicts of interest related to this article.

Received: 27 January 2020 Accepted: 16 July 2020

Published online: 07 October 2020

\section{References}

1. INSIGHT START Study Group, Lundgren JD, Babiker AG, Gordin F, Emery S, Grund B, et al. Initiation of antiretroviral therapy in early asymptomatic HIV infection. N Engl J Med. 2015;373(9):795-807.

2. World Health Organization. Guideline on when to start antiretroviral therapy and on pre-exposure prophylaxis for HIV. https://www.who.int/hiv/pub/ guidelines/earlyrelease-arv/en/. Accessed 12 Jan 2020.

3. World Health Organisation. Consolidated guidelines on HIV testing services. https://www.who.int/hiv/pub/guidelines/hiv-testing-services/en/. Accessed 12 Jan 2020.

4. Podlekareva D, Grint D, Karpov I, Vassilenko A, Rakmanova A, Mansinho K, et al. Changing utilization of Stavudine (d4T) in HIV-positive people in 20062013 in the EuroSIDA study. HIV Med. 2015;16(9):533-43.

5. Mocroft A, Lundgren J, Antinori A, Monforte AD, Brännström J, Bonnet F, et al. Late presentation for HIV care across Europe: update from the collaboration of observational HIV epidemiological research Europe (COHERE) study, 2010 to 2013. Eurosurveillance. 2015;20(47).

6. European Centre for Disease Prevention and Control. The status of the HIV response in the European Union/European economic area; 2016. https:// www.ecdc.europa.eu/en/publications-data/status-hiv-response-europeanunioneuropean-economic-area-2016. Accessed 12 Jan 2020.

7. Antinori A, Coenen T, Costagiola D, Dedes N, Ellefson M, Gatell J, et al. Late presentation of HIV infection: a consensus definition. HIV Med. 2011;12(1): $61-4$.

8. Mocroft A, Lundgren JD, Sabin ML, d'Arminio MA, Brockmeyer N, Casabona J, et al. Risk factors and outcomes for late presentation for HIV-positive persons in europe: results from the collaboration of observational HIV epidemiological research europe study (COHERE). PLoS Med. 2013;10(9): e1001510.

9. Chadborn TR, Delpech VC, Sabin CA, Sinka K, Evans BG. The late diagnosis and consequent short-term mortality of HIV-infected heterosexuals (England and Wales, 2000-2004). AIDS. 2006;20(18):2371-9.

10. Croxford S, Kitching A, Desai S, Kall M, Edelstein M, Skingsley A, et al. Mortality and causes of death in people diagnosed with HIV in the era of highly active antiretroviral therapy compared with the general population: an analysis of a national observational cohort. Lancet Public Health. 2017. 2(1):e35-46

11. Fleishman JA, Yehia BR, Moore RD, Gebo KA. The economic burden of late entry into medical Care for Patients with HIV infection. Med Care. 2010; 48(12):1071-9.

12. Attia S, Egger M, Müller M, Zwahlen M, Low N. Sexual transmission of HIV according to viral load and antiretroviral therapy: systematic review and meta-analysis. AIDS. 2009;23(11):1397-404.

13. Cohen MS, Chen YQ, McCauley M, Gamble T, Hosseinipour MC, Kumarasamy N, et al. Prevention of HIV-1 infection with early antiretroviral therapy. N Engl J Med. 2011;365(6):493-505.

14. Brännström J, Svedhem Johansson V, Marrone G, Wendahl S, Yilmaz A, Blaxhult $A$, et al. Deficiencies in the health care system contribute to a high rate of late HIV diagnosis in Sweden. HIV Med. 2016;17(6):425-35.

15. European Centre for Disease Prevention and Control. HIV/AIDS surveillance in Europe 2015. https://www.ecdc.europa.eu/sites/default/files/media/en/ publications/Publications/HIV-AIDS-surveillance-Europe-2015.pdf. Accessed $12 \operatorname{Jan} 2020$.

16. Gökengin D, Oprea C, Uysal S, Begovac J. The growing HIV epidemic in Central Europe : a neglected issue? J Virus Erad. 2016;2014:156-61.

17. Kowalska JD, Oprea C, de Witt S, Pozniak A, Gökengin D, Youle M, et al. Euroguidelines in central and Eastern Europe (ECEE) conference and the Warsaw declaration - a comprehensive meeting report. HIV Med. 2017; 18(5):370-5.

18. Drew R, Rice B, Rüütel $K$, Delpech V, Attawell $K$, Hales D, et al. HIV continuum of care in Europe and Central Asia. HIV Med. 2017;18(7):490-9.

19. European Centre for Disease Prevention and Control. Thematic report : HIV continuum of care. Monitoring implementation of the Dublin Declaration on Partnership to Fight HIV/AIDS in Europe and Central Asia: 2014 progress report. https://www.ecdc.europa.eu/sites/default/files/media/en/ publications/Publications/dublin-declaration-continuum-of-care-2014.pdf. Accessed 12 Jan 2020.

20. Laut K, Kirk O, Rockstroh J, Phillips A, Ledergerber B, Gatell J, et al. The EuroSIDA study: 25 years of scientific achievements. HIV Med. 2020;21(2):71-83.

21. Chêne G, Phillips A, Costagliola D, Sterne JAC, Furrer H, Amo J, et al. Cohort profile: collaboration of observational HIV epidemiological research Europe (COHERE ) in EuroCoord. Int J Epidemiol. 2017;46(3):797-797n.

22. www.hivrussia.ru. Accessed 12 Jan 2020.

23. Federal Scientific and Methodological Center for the Prevention and Control of AIDS of the Central Research Institute of Epidemiology of Rospotrebnadzor. www.crie.ru. Accessed 12 Jan 2020.

24. Eurostat. https://ec.europa.eu/eurostat/tgm/table.do?tab=table\&init= 1 \&language $=$ en\&pcode $=$ tps00001\&plugin=1. Accessed 12 Jan 2020.

25. The European Surveillance System (TESSy). https://www.ecdc.europa.eu/en/ publications-data/european-surveillance-system-tessy. Accessed 12 Jan 2020.

26. Vourli G, Pharris A, Cazein F, Costagliola D, Dabis F, Del Amo J, et al. Are European HIV cohort data within EuroCoord representative of the diagnosed HIV population? AIDS. 2019;33(1):133-43.

27. Raben D, Mocroft A, Rayment M, Mitsura VM, Hadziosmanovic V, Sthoeger ZM, et al. Auditing HIV testing rates across Europe: results from the hides 2 study. PLoS One. 2015;10(11):e0140845.

28. World Health Organization. Guidelines on HIV HIV Self-Testing and Partner Notification 2016. https://www.who.int/hiv/pub/self-testing/hiv-self-testingguidelines/en/. Accessed 12 Jan 2020.

29. Sullivan AK, Raben D, Reekie J, Rayment M, Mocroft A, Esser S, et al. Feasibility and effectiveness of indicator condition-guided testing for HIV: results from HIDES I (HIV indicator diseases across Europe study). PLoS One. 2013;8(1):e52845.

30. Lorente N, Fernandez-Lopez L, Fuertes R, Rojas Castro D, Pichon F, Cigan B, et al. COBA-cohort: a prospective cohort of HIV-negative men who have sex with men, attending community-based HIV testing services in five European countries (a study protocol). BMJ Open. 2016;6(7):e011314.

31. European Centre for Disease Prevention and Control. HIV Testing: increasing uptake and effectiveness in the European Union. https://www.ecdc.europa. eu/sites/default/files/media/en/publications/Publications/101129_GUI_HIV_ testing.pdf. Accessed 12 Jan 2020.

32. Tavoschi L, Gomes Dias J, Pharris A, Schmid D, Sasse A, Van Beckhoven D, et al. New HIV diagnoses among adults aged 50 years or older in 31 European countries, 2004-15: an analysis of surveillance data. Lancet HIV. 2017:4(11):e514-21. 
33. Pharris A, Quinten C, Tavoschi L, Spiteri G, Amato-gauci AJ, Aids HIV, et al, Trends in HIV surveillance data in the EU/EEA, 2005 to 2014: new HIV diagnoses still increasing in men who have sex with men. Euro Surveill. 2015;20(47).

34. The Joint United Nations Programme on HIV/AIDS (UNAIDS). Ending AIDS, Progress towards the 90-90-90 targets; 2017. https://www.unaids.org/en/ resources/documents/2017/20170720_Global_AIDS_update_2017. Accessed 12 Jan 2020.

35. Darling KE, Hachfeld A, Cavassini M, Kirk O, Furrer H, Wandeler G. Late presentation to HIV care despite good access to health services: current epidemiological trends and how to do better. Swiss Med Wkly. 2016; 146(August):w14348.

36. Hachfeld A, Ledergerber B, Darling K, Weber R, Calmy A, Battegay M, et al. Reasons for late presentation to HIV care in Switzerland. J Int AIDS Soc. 2015;18(1):1-8.

37. Power L, Hows J, Jakobsen S, Von Lingen A. Barring the Way to Health: How Legal \& Regulatory Barriers are Hindering Modernising HIV Testing across Europe. HepHIV 2017 Conference, Malta. Poster No PS4/02. Available at: http://www.eurotest.org/Portals/0/Conference\%202017/Posters/PS4_02.pdf. Accessed 22 July 2020.

38. European Centre for Disease Prevention and Control. HIV testing in Europe. Evaluation of the impact of the ECDC guidance on HIV testing: increasing uptake and effectiveness in the European Union. https:/www.ecdc.europa. eu/sites/portal/files/media/en/publications/Publications/HIV-testingguidance-evaluation.pdf. Accessed 12 Jan 2020.

39. van Opstal SEM, van der Zwan JS, Wagener MN, Been SK, Miedema HS, Roelofs PDDM, et al. Late presentation of HIV infection in the Netherlands: reasons for late diagnoses and impact on vocational functioning. AIDS Behav. 2018;22(8):2593-603.

40. Lewden C, Bouteloup V, De Wit S, Sabin C, Mocroft A, Wasmuth JC, et al. All-cause mortality in treated HIV-infected adults with CD4 $\geq 500 / \mathrm{mm} 3$ compared with the general population: evidence from a large European observational cohort collaboration. Int J Epidemiol. 2012;41(2):433-45.

41. Reekie J, Kowalska JD, Karpov I, Rockstroh J, Karlsson A, Rakhmanova A, et al. Regional differences in AIDS and non-AIDS related mortality in HIVpositive individuals across Europe and Argentina: the EuroSIDA study. PLoS One. 2012;7(7):e41673.

42. European Centre for Disease Prevention and Control. Continuum of HIV care. Monitoring implementation of the Dublin Declaration on Partnership to Fight HIV/AIDS in Europe and Central Asia: 2018 progress report https:// www.ecdc.europa.eu/sites/default/files/documents/HIV-continuum-of-caremonitoring-dublin-declaration-progress-report-2018.pdf. Accessed 12 Jan 2020

\section{Publisher's Note}

Springer Nature remains neutral with regard to jurisdictional claims in published maps and institutional affiliations.

Ready to submit your research? Choose BMC and benefit from:

- fast, convenient online submission

- thorough peer review by experienced researchers in your field

- rapid publication on acceptance

- support for research data, including large and complex data types

- gold Open Access which fosters wider collaboration and increased citations

- maximum visibility for your research: over $100 \mathrm{M}$ website views per year

At BMC, research is always in progress.

Learn more biomedcentral.com/submissions 